\title{
PENGARUH DAYA SAING PERUSAHAAN DAN FREE \\ FLOW OF SKILL LABOUR DALAM ECONOMIC ANALYSIS \\ OF LAW
}

Iwan Sandi Pangarso, S.H, M.H.

Universitas Muhammadiyah Gresik

Iwansandipangarso@umg.ac.id

\begin{abstract}
With the ease with which the permission of Foreign Workers (TKA) to enter Indonesia is expected to have a positive influence both for individuals, companies and for the country. The ease of permitting foreign workers can also be a way for investors to invest in Indonesia where investments made will be very profitable for the country. With the ease of Foreign workers permits, it is expected to be a trigger for the people of Indonesia to continue to develop and advance so as not to be left behind by the Foreign Workers and be able to develop companies in Indonesia more advanced so as not to make alternative foreign workers for company development. In relation to the competitiveness of companies, selected foreign workers must be able to develop the company so that they are able to compete in the world economy. Thus Indonesian workers and workers must be able to work together in producing new alternatives that can be developed in Indonesia, with the same welfare so as not to trigger discrimination between the two parties concerned. The government here has a very important role in everything, especially in the welfare of its people, here is done by opening up employment opportunities and guaranteeing all the welfare of its people by paying attention to the existing work by increasing the nominal salary in order to improve welfare for all levels of society especially people who are in the lowest layer.
\end{abstract}

Keywords: Company Competitiveness, Free Flow and Skill Labor 


\section{Latar Belakang Masalah}

Dalam kaitannya dengan ASEAN Economic Community (AEC 2015), Indonesia sendiri telah lama bergambung didalamnya sejak kesepakatan tersebut dibuat. AEC sendiri adalah peraturan yang dibuat oleh 10 kepala negara ASEAN demi meningkatkan perekonomian negara melalui pembebasan tenaga kerja terlatih untuk mencari pekerjaan di luar negaranya. Demi meningkatkan pendapatan setiap negara, maka negara tersebut memberikan kemudahan bagi warga negara asing untuk mencari lapangan pekerjaan di negaranya.Pada hakikatnya dengan adanya peraturan seperti ini, jika tidak diseimbangkan dengan keadaan negaranya masing-masing juga akan berdampak pada meningkatnya angka pengangguran di setiap negara. Seperti halnya di Indonesia, jika pemerintah tidak memberikan keseimbangan maka yang ada hanya akan menimbulkan banyaknya angka pengangguran dan angka kriminalitas di Indonesia. Seperti yang di terangkan pada pasal 27 ayat 2 bahwasannya setiap warga negara berhak atas pekerjaan dan penghidupan yang layak bagi kemanusiaan. Dalam pasal tersebut sudah jelas menerangkan bahwa pemerintah bertanggung jawab atas penghidupan yang layak setiap warganya.

Dengan adanya ASEAN Economic Community maka setiap negara di tuntut untuk mengembangkan suatu negaranya terutama di bidang jasa dan pengembangan perusahaan-perusahaan untuk mensejahterahkan para penduduknya dengan cara membuka lapangan pekerjaan secara luas dan menyeluruh sehingga bisa di akses oleh semua orang, tidak ketercuali tenaga kerja asing yang 
ingin bekerja di perusahaan indonesia, akan tetapi hal tersebut harus melewati berbagai proses dan persetujuan dari negara asalnya.

Walaupun semakin pesatnya pertumbuhan ekonomi dunia, pemerintah juga tidak boleh egois dengan hanya memikirkan keuntungan bagi negara saja. Pemerintah seharusnya mempertimbangkan bagaimana cara memberikan penghidupan yang layak bagi setiap warganya dengan tidak mengesampingkan pertumbuhan ekonomi. Setiap keputusan yang diambil oleh pemerintah haruslah memberikan dampak yang baik bagi setiap warganya, dengan begitu keseimbangan antara kebebasan dalam perekonomian yang menyangkut kemudahan tenaga kerja asing dalam mencari pekerjaan dan penghidupan yang layak bagi warga negara dapat berjalan dengan baik. Demi meningkatkan dan mengikuti perkembangan perekonomian, Indonesia membuat peraturan baru mengenai tenaga kerja asing dimana peraturan tersebut terdapat dalam Perpres No. 20 Tahun 2018 tentang Penggunaan Tenaga Kerja Asing (TKA), dengan adanya perpres ini maka izin Tenaga Kerja Asing (TKA) semakin mudah masuk ke Indonesia.Perpres tersebut adalah pengganti dari perpres sebelumnya yaitu Perpres No. 72 tahun 2014 tentang Penggunaan tenaga kerja asing Serta Pelaksanaan Pendidikan dan Pelatihan Tenaga Kerja Pendamping.Perpres pengganti tersebut diharapkan dapat menjadi jawaban bagi warga negara dalam mendapatkan penghidupan yang layak. 
Kehidupan yang layak dalam hal ini sangat ditekankan karena kehidupan yang layak adalah suatu harapan bagi tenaga kerja, dengan adanya kehidupan yang layak akan berdampak positif bagi kesejahteraan warga negara, dengan kesejahterah an yang layak akan memicu adanya ide-ide baru yang bisa dikembangkan dan bisa di wujudkan di dalam suatu perusahaan, untuk itu maka suatu perusahaan wajib memperhatikan kelayakan hidup buat para pegawainya, karena hal ini akan memicu tingkat keberhasilan suatu perusahaan serta berkembangnya suatu perusahaan.

Dengan munculnya perpres No. 20 Tahun 2018 memicu perdebatan antar kalangan baik dari kalangan pemerintah maupun dari kalangan para buruh. Dimana sudut pandang yang diambil atau yang mereka kemukakan berbeda-beda. Jika dilihat dari sudut pandang para buruh, maka yang ada perpres tersebut dapat mengakibatkan persaingan dalam pencarian pekerjaan dikarenakan para tenaga kerja asing akan mendapatkan pekerjaan dengan mudah dikarenakan sudah mendapatkan rekomendasi dari pemberi tenaga kerja. Sedangkan warga negara Indonesia harus mengalami kesusahan demi mendapatkan pekerjaan. Jika dilihat dari sudut pandang pemerintah, dengan dipermudahnya tenaga kerja asing maka mempermudah juga bagi investor-investor dari negara asing untuk berinvestasi di Indonesia dan menciptakan lapangan pekerjaan bagi warga Indonesia. Dengan seperti itu maka tidak menutup kemungkinan kalau kedepannya nanti tenaga kerja asli indonesia akan tereliminasi dengan sendirinya kalau mereka tidak mempunyai kemampuan yang di inginkan oleh para perusahaan, 
karena dalam hal ini tenaga kerja indonesia akan bersaing dengan tenaga kerja seluruh dunia.

Hal yang paling ditakuti adalah ketika tenaga kerja di indonesia tidak mempunyai keahlihan yang memadai, sehingga kalah dengan tenaga kerja asing yang sudah dibekali keahlihan-keahlihan yang sangat mempuni. Dengan ini tenaga kerja indonesia akan secara tidak langsung tereliminasi dengan adanya penetapan standart keahlihan bagi pegawai, peluang ini akan dijadikan senjata para tenaga kerja asing untuk masuk ke indonesia dan bekerja di indonesia.

\section{Rumusan Masalah}

Pengaruh daya saing perusahaan dan Free Flow of Skill Labour dalam Economic Analysis of Law. Perlu dievaluasi kembali dalam penerapan, manfaat dan dampaknya dalam perekonomian Indonesia. Dimana perpres tersebut adalah ujung tombak dalam kebebasan izin tenaga kerja untuk mendapatkan pekerjaan di Indonesia.

\section{Analisa dan Pembahasan}

\section{A. Alassan Ekonomi Terhadap Perpres Tenaga Kerja Asing}

Perpres tenaga kerja asing jika dihubungkan dengan alasan ini, dengan adanya tenaga kerja asing diharapkan kemudahan berbisinis di Indonesia semakin berkembang dan dapat meningkatkan perekonomian negara. Perekonomian negara bertambah berdampak juga ke devisa negara kian meningkat. Dimana tenaga kerja asing yang bekerja untuk perusahaan Indonesia dituntut untuk menciptakan ide-ide baru yang dapat 
meningkatkan kemajuan perusahaan. tenaga kerja asing yang terpilih untuk meningkatkan perusahaan adalah tenaga kerja asing -tenaga kerja asing yang memiliki spesifikasi dibidangnya yang telah ditentukan dan dipilih oleh perusahaan tersebut. Dengan berkembangnya dan sistem baru yang mendukung perkembangan perusahaan diharapkan dapat meningkatkan nilai perusahaan tersebut dimata dunia.

Dengan berkembangnya suatu perusahaan akan meningkatkan kestabilitasan di dalam suatu perusahaan dan akan berdampak ke negara, sehingga dalam hal ini di harapkan perkembangan suatu negara bisa berkembang dengan pesat serta bisa meningkatkan kestabilan perusahaan dan negara.

Tenaga kerja asing disini akan dipilih dengan ketat dan di berikan nilai standart agar tenaga kerja asing yang akan di pekerjakan mempunyai kemampuan yang standart guna kepentingan suatu perusahaan, yang akan berdampak bagi tenaga kerja indonesia agar bisa di pelajari ilmunya seiring dengan berjalnnya waktu.

Perpres tenaga kerja asing jika dihubungkan dengan alasan ini, dengan dipermudahnya izin tenaga kerja asing diharapkan dapat membawa para investor dari luar negeri untuk berinvestasi didalam negeri. Dengan investasi yang dilakukan atau ditanamkan para investor di suatu perusahaan dapat meningkatkan nilai perusahaan dan dapat meningkatkan profitabilitas baik untuk perusahaan tersebut maupun untuk negara.

Dengan mempermudahnya izin tenaga kerja asing maka dengan itu bisa mengundang investasi asing yang masuk ke 
indonesia dengan mudah, dan meningkatkan investasi di indonesia karena para investor menanamkan modalnya. Dengan demikian maka tujuan utama dari memperkerjakan tenaga kerja asing bisa terealisasi dengan baik.

Investor-investor asing akan berlomba-lomba menanamkan modalnya untuk indonesia karena tenaga kerja mereka bekerja di indonesia, maka tingkat kepercayaan intuk berinvestasi akan semangkin banyak, dan berpotensi besar untuk meningkatkan investasinya melalui tenaga kerjanya maupun hal-hal yang lain, serta kerjasama di antara kedua belah pihak negara.

Perpres tenaga kerja asing jika dihubungkan dengan alasan ini, dengan danya perpres ini diharapkan para tenaga kerja asing dapat menciptakan lapangan pekerjaan bagi rakyat Indonesia. Dimana para tenaga kerja asing yang masuk adalah para tenaga kerja asing yang memiliki spesifikasi yang mumpuni dan dpat menciptakan lapangan pekerjaan baru bagi rakyat Indonesia. Sehingga keseimbangan antara perpres tenaga kerja asing dan hak penghidupan yang layak bagi warga negara Indonesia terpenuhi.

Dengan adanya persaingan antara tenaga kerja asing dan tenaga kerja indonesia akan di harapkan menimbulkan suatu lapangan pekerjaan baru untuk tenaga kerja indonesia, dengan membuka lahan-lahan pekerjaan yang baru dan dapat berguna bagi masyarakat indonesia. Lapangan pekerjaan bukan hanya dari suatu perusahaan, melainkan bnyak hal yang bisa membuat lapangan pekerjaan baru, misalnya dengan membuka home 
industri maupun memanfaatkan ke krearifitasan masyarakat setempat dengan keahlihannya masing-masing.

Free flow of skill labour merupakan salah satu pilar utama dalam ASEAN Economic Community (AEC). Dimana free flow of skill labour adalah hal yang paling disoroti dalam AEC, dikarenakan dengan semakin terbukanya dan mudahnya izin bagi tenaga kerja asing dalam mencari pekerjaan dinegara lain dapat meningkatkan pendapatan bagi negara asalnya.

Dengan dipermudahnya izin bagi tenaga kerja asing untuk mencari pekerjaan di negara lain, diharapkan juga dapat meningkatkan minat para investor untuk berinvestasi di negara tersebut dan bersama-sama mendapatkan dampak yang positif dari mudahnya izin tenaga kerja asing. Karena tujuan utama dalam hal ini adalah untuk meningkatkan kesejahteraan bagi masyarakat dan memajukan dunia perdagangan dengan sistem penggeraknya adalah tenaga kerja asing dan tenaga kerja lokal.

Izin adalah hal yang paling utama dalam masuknya tenaga kerja asing, karena dengan di permudahkan nya izin masuk ke negara-negara lain maka dengan begitu akan meningkatkan minat tenaga kerja asing untuk masuk kedalam suatu negara tersebut, sehingga dengan masuknya tenaga kerja asing maka akan meningkatkan skil dan hasil dari suatu prodak perusahaan, karena tenaga kerja asing sudah di bekali dengan skil-skil khusus.SWorld economic forum mendefinisikan daya saing sebagai kombinasi dari institusi, kebijakan, dan faktor yang menentukan tingkat produktivitas suatu negara (World economic forum, 2016) 
Teori ini menyatakan bahwa tingkat produktivitas akan menentukan tingkat kemakmuran yang dapat dicapai oleh suatu perekonomian. Tingkat produktivitas juga menentukan tingkat pengembalian investasi dalam perekonomian yang pada akhirnya menjadi pendorong fundamental dari pertumbuhan ekonomi. Dengan kata lain, negara yang berdaya saing akan cenderung memiliki pertumbuhan ekonomi yang lebih cepat. Semangkin bagus daya saing di dalam suatu negara tersebut akan membuat semangkin bagus pula pertumbuhan ekonomi kedepannya nanti.

Yang dimaksud daya saing disini adalah, keahlihan yang dimiliki oleh para pegawai, serta pengalaman yang sudah dilaluinya di dalam dunia pekerjaan, apabila itu semua tidak dimiliki oleh tenaga kerja indonesia akan berdampak negatif bagi suatu perusahaan, sehingga tidak menutup kemungkinan akan memakai tenga kerja asing.

\section{B. Alasan Hukum Terhadap Perpres Tenaga Kerja Asing}

Dalam kaitannya dengan pasal 27 ayat 2 dimana warga negara berhak mendapatkan pekerjaan dan penghidupan yang layak, maka diharapkan dengan dipermudahnya izin tenaga kerja asing memberikan dampak positif. Dimana dampak tersebut berkaitan dengan kesejahteraan individu. Setiap individu berhak atas kesejahteraannya dan penghidupan yang layak. Dengan kesejahteraan yang didapatkan dalam bentuk pekerjaan diharapkan dapat mengurangi pengangguran dan juga tingkat kriminalitas yang ada. 
Dengan meminimalisir tingkat pengangguran akan berdampak pula terhadap penurunan kriminalitas di suatu daerah tersebut, dengan berkurangnya tingkat kriminalitas akan meningkatkan kesejahteraan bagi masyarakat, sehingga bisa mempengaruhi daya berfikir seseorang untuk melakukan perbuatan yang positif dan menghilangkan pemikiran yang negatif.

Dalam hal ini negara beperan sangat aktif karena negara harus memberi kehidupan yang layak bagi kehidupan rakyatnya, dengan cara memberikan lapangan pekerjaan yang layak dan bisa di akses oleh semua orang terutama warga negara indonesia, dan mendapatkan upah yang sesuai dengan bidang dan keahlihannya masing-masing di dalam suatu perusahaan, serta memberikan apresiasi atas suatu kinerjanya yang di nilai sangat positif dan bisa berguna bagi masyarakat luas.

Dalam kaitannya dengan perpres No. 20 Tahun 2018 yang menyangkut tenaga kerja asing dapat menciptakan keadilan bagi para tenaga kerja asing indonesia yang bekerja diluar negeri. Dimana, jika Indonesia mempermudah tenaga kerja asing masuk dan mendapatkan kerja maka diharapkan negara lain juga dapat memberikan kesempatan bagi rakyat Indonesia untuk mendapatkan pekerjaan di negaranya. Bukan hanya mempermudah dalam mendapatkan pekerjaan saja, tetapi diharapkan dapat memberikan keadilan juga bagi rakyat Indonesia yang bekerja di luar negeri untuk mendapatkan hak-haknya ketika bekerja. 
Dalam keterkaitn perpres No 20 tahun 2018 maka hal yang paling utama yang harus dilakukan adalah mensejahterahkan masyarakat lewat penyejahterah an upah minimum gaji, sehingga dapat mensejahterahkan masyarakat berada di level menengah dalam hal kesehatan, pangan serta hal-hal lain yang sifatnya sangat krusial di mata negara.

Yang di maksud distributif disini adalah suatu keadilan bagi masyarakat indonesia yang bekerja di luar negri, karena dengan mendapatkan perlindungan hukum yang reel maka dengan itu bisa menjamin kehidupan tenaga kerja indonesia yang bekerja di luar negri, dengan jaminan seperti itu maka kesejahteraan tenaga kerja di indonesia di luar negri akan terjamin dan bisa hidup dengan layak.

Daya saing perusahaan adalah kemampuan sebuah perusahaan untuk membuat dan memformulasikan berbagai macam strategi yang bisa menempatkannya pada suatu posisi yang strategis dan lebih menguntungkan jika dibandingkan dengan perusahaan lainnya. (Tangkilisan:2003)

Teori ini menyatakan bahwa perusahaan haruslah memiliki kemampuan untuk membuat strategi dalam mendapatkan keuntungan yang lebih banyak dibandingkan dengan perusahaan lainnya dengan cara melihat pangsa pasar yang ada.Strategi bersaing adalah mengembangkan rencana mengenai bagaimana bisnis akan beraing, apa yang seharusnya menjadi tujuannya dan kebijakan apa yang diperlukan untuk mencapai tujuan tersebut. (Michael Porter, 2001) 
Pokok dalam strategi bersaing adalah menghubungkan perusahaan dengan lingkungannya, walaupun lingkungan tersebut relevan luas, yang dapat meliputi kekuatan-kekuatan sosial dan ekonomi. Daya saing strategi merupakan alat perusahaan untuk bersaing dengan penantang pasar, daya saing strategis ini muncul ketika sebuah perusahaan menerapkan strategi penciptaan nilainilai yang tidak dapat ditiru manfaatnya oleh perusahaan lain atau teralu tinggi harganya untuk ditiru.

Semangkin bersaing di dalam dunia pekerjaan maka semangkin bersing pula dalam hal yang dihasilkan suatu produk dengan begitu maka hasil akhir dalam suatu perusahaan akan di pertimbangkan untuk memajukan perusahaan tersebut. Dengan hal ini diperlukan tenaga kerja yang profesional di bidangnya dan bisa di andalkan, sehingga bisa memajukan suatu perusahaan dengan bagus.

Teori-teori ini akan di terapkan di dalam dunia pekerjaan terutama bagi tenaga kerja asing, sehingga tenaga kerja asing sudah di bekali dengan kemampuan yang standart, begitu pula tenaga kerja indonesia harus dibekali dengan kemampuankemampuan yang standart guna kepentingan suatu perusahaan, agar bisa memajukan suatu perusahaan yang di tempati untuk bekerja.

\section{Kesimpulan}

Dalam uraian yang telah disampaikan sebelumnya, bahwasanya dengan dipermudahnya izin Tenaga Kerja Asing (TKA) masuk ke Indonesia diharapkan memiliki pengaruh yang positif baik untuk individu, perusahaan maupun untuk negara. 
Dipermudahnya izin tenaga kerja asing juga dapat menjadi jalan bagi para investor untuk berinvestasi di Indonesia dimana investasi yang dilakukan akan sangat menguntungkan bagi negara. Dengan dipermudahnya izin TKA, diharapkan menjadi pemicu bagi rakyat Indonesia untuk terus berkembang dan maju agar tidak tertinggal oleh Tenaga Kerja Asing tersebut dan mampu mengembangkan perusahaan-perusahaan yang ada di Indonesia lebih maju lagi agar tidak menjadikan para TKA alternatif untuk pengembangan perusahaan. Dalam kaitannya dengan daya saing perusahaan, TKA yang terpilih haruslah mampu mengembangkan perusahaan sehingga mampu bersaing dalam perekonomian dunia. Dengan demikian TKA dan tenaga kerja Indonesia harus mampu berkerja sama dalam menghasilkan suatu alternatif-alternatif yang baru dan bisa di kembangkan di Indonesia, dengan kesejahteraan yang sama sehingga tidak memicu adanya diskriminasi antara kedua belah pihak yang bersangkutan.

Pemerintah di sini perannya sangat dibutuhkan dalam segala hal, terutama dalam kesejahteraan bagi masyarakatnya, di sini dilakukan dengan cara membuka lapangan pekerjaan yang mempuni dan menjamin semua kesejahteraan bagi masyarakatnya dengan cara memperhatikan pekerjaan yang ada dengan meningkatkan nominal gaji agar bisa meningkatkan kesejahteraan bagi semua lapisan masyarakat terutama masyarakat yang berada dalam lapisan terbawah.

Penulis dalam hal ini menginginkan tingkatn kesejahteraan bagi para pegawai lokal, dengan cara menyamakan fasilitas yang 
ada antara tenaga kerja asing dengan tenaga kerja lokal, sehingga tidak ada diskriminasi antara kedua nya, selain itu tingkat kesejahteraan berupa upah minimum juga harus disetarakan agar tidak akan ada kecemburuan sosial, serta lebih menghargai tenaga kerja lokal, dan memperbanyaktenaga kerja lokal di bandingkan tenaga kerja asing, serta menempatkan tenaga kerja lokal di posisi posisi yang lebih menguntungkan dari pada tenaga kerja asing.

\section{Daftar Pustaka}

Amiruddin dan H.Zainal Aasikin, 2010, Pengantar Metode Penelitian Hukum, Rajawali Pers, Jakarta

Azhari, Aidul Fitriciada, 2000, Sistem Pengambilan Keputusan Demokrasi Menurut Konstitusi, Muhammadiyah University Press, Surakarta

Ball, Alan R.\&B, Guy Peters, 2000, Modern Politics And Government, edisi ke-6 Macmillan Press Ltd.

Darminto Harminto, Economic Aanalysis Of Law Atas Putusan PKPU Tetap, Cet.I (Lembaga Studi Hukum dan Ekonomi Fakultas Hukum, Jakarta, 2009).

Fajar Sugianto, 2013, Economic Analysis Of Law:Seri Analisa Keekonomian Tentang Hukum, Kencana

Gordon, scott, 1999. Controlling the State: Constitutionalism From Ancient Adhens to Today, Harvard University Press

Latif, Abdul, 2007, Fungsi Mahkahma Konstitusi Dalam Upaya Mewujudkan Negara Hukum Demokrasi, Total Media, Yogyakarta.

Munir Fuady. 2002. Perbuatan Melawan Hukum. Cetakan 1. Bandung: Citra Aditya Bakti. 
Nasution, H.Ny. Rumonda. 1992. Harta Kekayaan Suami Istri dan Kewarisanya. Jakarta: BPHN.

P.N.H. Simanjuntak. 2008. Pokok-Pokok Hukum Perdata Indonesia. Jakarta: Djambatan.

Pipin Syarifin. 1999. Pengantar Ilmu Hukum. Bandung. Pustaka Setia

R. Setiawan. 1987. Pokok-Pokok Hukum Perikatan. Bandung: BinaCipta. 